Original Article

\title{
Change the Myofascial Pain and Range of Motion of the Temporomandibular Joint Following Kinesio Taping of Latent Myofascial Trigger Points in the Sternocleidomastoid Muscle
}

\author{
Youngsook BAE, $\mathrm{PT}^{1)}$ \\ 1) Department of Physical Therapy, College of Health Science, Gachon University: Yeonsu-dong, \\ Yeonsu-gu, Incheon, Republic of Korea
}

\begin{abstract}
Purpose] The purpose of this study was to identify the changes in the myofascial pain and range of the motion of temporomandibular joint when Kinesio taping is applied to patients with latent myofascial trigger points of the sternocleidomastoid muscle. [Subjects and Methods] The subjects were 42 males and females aged 20 to 30 years (male 17, female 25). They were randomly divided into the control group and the experimental group, which would receive Kinesio taping. Kinesio taping was applied to the sternocleidomastoid muscle three times per week for two weeks. The pain triggered when the taut band or nodule was palpated was measured. Pain intensity was measured using the visual analog scale (VAS) and pressure pain threshold (PPT). The range of motion of the temporomandibular joint was measured. In all subjects, VAS, PPT, and range of motion of the temporomandibular joint were measured before and after the intervention. [Results] In the experimental group, it was found that pain in the SCM was relived, as the VAS and PPT score decrease significantly and range of motion of temporomandibular joint increase significantly. In comparison between the groups, significant differences were shown in the VAS and PPT scores and in the range of motion of the temporomandibular joint. [Conclusion] Kinesio taping is thought to be an intervention method that can be applied to latent myofascial trigger points.

Key words: Kinesio taping, Latent myofascial trigger point, Sternocleidomastoid muscle
\end{abstract}

(This article was submitted Jan. 29, 2014, and was accepted Feb. 20, 2014)

\section{INTRODUCTION}

Myofascial pain syndrome is a general muscle condition triggered by myofascial trigger points ${ }^{1)}$. The trigger points are said to be attributable to repetitive stress, lack of exercise, sleep disturbance, and joint problems and they are classified as being active or latent, depending on their clinical characteristics ${ }^{2}$. Active trigger points refer to those points at which referred pain is triggered when a taut band is pressed, while latent trigger points refer to those points at which referred pain is triggered when direct pressure is applied $^{3)}$. Latent trigger points may appear in persons with musculoskeletal pain and may lead to muscle weakness, restricted movement, distorted muscle movement patterns, stiffness and weakness of the affected muscle ${ }^{4)}$. Latent trigger points may develop into active trigger points over time $^{3,5)}$

The sternocleidomastoid (SCM) muscle is a paired muscle in the superficial layers of the anterior portion of the

Corresponding author. Youngsook Bae (E-mail: baeys@ gachon.ac.kr)

(C2014 The Society of Physical Therapy Science. Published by IPEC Inc. This is an open-access article distributed under the terms of the Creative Commons Attribution Non-Commercial No Derivatives (by-ncnd) License $<$ http://creativecommons.org/licenses/by-nc-nd/3.0/> . neck, and it is one of the largest and most superficial cervical muscles. The function of this muscle is rotation of the head to the opposite side or oblique rotation of the head. It also flexes the neck ${ }^{6}$, and it is a posture-maintaining muscle that plays important roles in maintaining balance between the head and the muscles at the rear of the neck, maintaining the stability of the head, and maintaining head postures ${ }^{7}$. Among the neck muscles, the SCM induces the most co-contraction during maximal clenching of the temporomandibular joint ${ }^{8)}$. It acts in close coordination with the cervical muscles ${ }^{9)}$. Therefore, the SCM can be said to be a factor that may affect the range of motion of the temporomandibular joint (ROM of the TMJ) along with the muscles that move the chin.

Posture maintaining muscles such as the SCM muscle may be under excessive stress for a long time due to repetitive and habitual postures resulting in myofascial trigger points $(\mathrm{MTrPs})^{10)}$. MTrPs are described as hyperirritable spots in skeletal muscle that are associated with palpable nodules in taut bands of muscle fibers ${ }^{11)}$. Trigger points form as a local contraction in a small number of muscle fibers in a larger muscle or muscle bundle ${ }^{12}$. Therefore, pain may be triggered in posture-maintaining muscles such as the SCM due to MTrPs, resulting in not only problems in cervical spine movements but also restriction of the ROM of the TMJ. 
Therefore, the purpose of this study was to identify the long-term effect on the myofascial pain at latent MTrPs and changes in the ROM of the TMJ when Kinesio taping ${ }^{13)}$ was applied to patients with latent MTrPs of the SCM muscle as a method that can be easily used to relieve pain in the musculoskeletal system and recover muscle functions to a normal level by strengthening weakened muscles.

\section{SUBJECTS AND METHODS}

\section{Subjects}

This study was conducted with 42 males and females aged 20-30 years (male 17, female 25). Experienced physical therapists selected subjects with latent MTrPs in the SCM muscle. To examine latent MTrPs in the SCM muscle, the subjects lied on a treatment table in a supine position and their head in the direction opposite to the side of the affected SCM muscle. The trigger point diagnosis criteria was as follows; 1) palpable taut bands present in the skeletal muscles, 2) hypersensitive spots present in the taut bands, 3) palpable or visible local twitch on snapping palpation, and 4) referred pain triggered when a sensitive spot was palpated $^{11)}$

The minimum criteria for latent MTrPs identification in this study were, 1) palpable taut bands or nodules present in the skeletal muscles and 2) hypersensitive tender spots present in the taut bands in the skeletal muscles. These minimum criteria are the most reliable diagnostic criteria for MTrPs identification ${ }^{14)}$. Inclusion criteria for the subjects were presence of any latent trigger point in the left or right unilateral SCM muscle, restriction of the ROM of the TMJ, or crepitation or inconvenience during mastication. The exclusion criteria were presence of had any experience of trauma, any latent trigger point caused by the same reason, restriction of the ROM of the TMJ caused by any systematic disease such as arthritis, and treatment to release the SCM muscle or to relieve pain within several months before the time of examination.

The subjects were randomly divided into an experimental group that would receive Kinesio taping and a control group that would not receive Kinesio taping. In addition, the subjects were selected from among those who understood the purpose of this study and were capable of understanding and complying with the tester's instructions. All subjects understood the purpose of this study and agreed to participate in this research. All participants signed an informed consent form approved by the Institutional Review Board.

\section{Methods}

As the pain in the latent MTrPs in the SCM muscle, the pain triggered when a taut band or nodule was palpated was measured. Pain intensity was measured using the visual analog scale (VAS) and the pressure pain threshold (PPT). The VAS was used to measure the pain triggered when the taut band or nodule was palpated. The VAS is a tool for measuring musculoskeletal pain with excellent reliability and validity ${ }^{15)}$. The VAS is usually a horizontal line $100 \mathrm{~mm}$ in length that divides pain into grades 0 to100 ranging from
0 for no pain to 100 for unbearable pain, and subjects are asked to indicate the pain they feel by indication a spot on the horizontal line.

The PPT is a tool valid and highly reliable in clinical studies of pain related to myofascial and musculoskeletal pain problems ${ }^{16)}$. After vertically placing a PPT on the belly of the patient's SCM muscle on the affected side, the tester gradually applied pressure to the belly at a pressure level of $0.2 \mathrm{lbs}$, and then held the pressure level for five seconds. At the moment when pain began, the tester paused and recorded the indicated pressure. The experiment was repeated three times, and the average of the measured values was used for the analysis value. The measurement unit was $\mathrm{kg} / \mathrm{cm}^{2}$.

The ROM of the TMJ was measured in millimeters ( $\mathrm{mm}$ ) as the distance between the median clefts of the upper and lower teeth using a goniometry ${ }^{17}$.

The control group received no intervention, and the experimental group received Kinesio taping on SCM muscle. Kinesio taping was applied to the SCM three times per week for two weeks. The subjects performed light SCM muscle stretching before attachment of the tapes and were instructed to leave the tape attached until the next treatment session. The Kinesio tape use in this study was $5 \mathrm{~cm}$ wide. To apply the tapes to the SCM, the subjects turned their head away from the side on which the tape was to be applied and bent their neck laterally in a sitting position, and the base of the tape was attached to the mastoid process. Thereafter, the tape was attached in a "Y-shape" to the clavicular portion and sternal portion ${ }^{18)}$. VAS, PPT, and ROM of the TMJ were measured in all subjects before and two weeks after the taping period.

Statistical analyses were performed using SPSS version 14 for Windows (SPSS Institute Korea, Seoul, South Korea), and the results are presented as the mean \pm SD. In order to analyze the changes in PPT and VAS score for pain intensity in the SCM muscle and in ROM of the TMJ between before and after the taping period, the paired t-test was used to examine the changes within each group, and an independent t-test was used for comparison among the two groups. Statistical significance was accepted for values of $\mathrm{p}<0.05$.

\section{RESULTS}

Twenty-three subjects were assigned to the experimental group, and 19 subjects were assigned to the control group. The general characteristics of the subjects are shown in Table 1. After applying Kinesio taping to the subjects with latent MTrps and restriction of the ROM of the TMJ, it was found that pain in the SCM muscle was relieved, as the VAS score and PPT decreased significantly $(\mathrm{p}<0.01$ and $\mathrm{p}<0.05$, respectively). The ROM of the TMJ increase significantly $(\mathrm{p}<0.05)$. These results indicated that Kinesio taping was effective on pain triggered in latent MTrPs as a result from excessive stress on the SCM muscle and that as excessive stress on the SCM muscle decreased, the ROM of the TMJ also changed. On the other hand, the control group did not show any change between before and after the taping period. Comparison between the groups revealed significant 
Table 1. Characteristics of subjects

\begin{tabular}{lccc}
\hline & $\begin{array}{c}\text { Control group } \\
(\mathrm{n}=19)\end{array}$ & $\begin{array}{c}\text { Experimental group } \\
(\mathrm{n}=23)\end{array}$ & $\begin{array}{c}\text { All subjects } \\
(\mathrm{n}=42)\end{array}$ \\
\hline Female & 11 & 14 & 25 \\
Male & 8 & 9 & 17 \\
Age (year) & $22.8 \pm 3.2$ & $23.3 \pm 2.7$ & $23.1 \pm 3.0$ \\
Weight $(\mathrm{kg})$ & $59.9 \pm 13.7$ & $61.3 \pm 12.2$ & $61.2 \pm 12.4$ \\
Height $(\mathrm{cm})$ & $165.2 \pm 10.5$ & $167.5 \pm 11.9$ & $166.9 \pm 12.4$ \\
\hline
\end{tabular}

differences in VAS and PPT scores, and in the ROM of the TMJ $(\mathrm{p}<0.05)$ (Table 2).

\section{DISCUSSION}

This study was conducted to identify the long-term effect on myofascial pain and the ROM of the TMJ when Kinesio taping was applied to subjects with latent MTrPs in their SCM muscle. According to the study results, after applying Kinesio taping to the SCM muscle, the myofascial pain was relieved and the ROM of the TMJ increased.

Kinesio taping can be used to manage muscle strength, and its cutaneous afferent stimulation is said to be correlated with motor unit firing ${ }^{19)}$. It is a method that can be easily used to improve proprioception by increasing stimulation of the mechanoreceptors of the skin $^{20)}$, relive pain, and recover muscle functions to a normal level by strengthening weakened muscles ${ }^{13)}$. In addition, Kinesio taping is said to be capable of affecting the fascia and lymph fluid flows, and thus it can be applied as the only method of relieving pain and promoting healing ${ }^{21)}$. Pain was relieved after Kinesio taping was applied to latent trigger points of the SCM muscle in this study. Application of Kinesio tape applied to latent trigger points resulting from continued stress, such as incorrect postures, is thought to have increased stimulation of the mechanoreceptors on the skin to improve proprioception and recover muscle functions to a normal level by strengthening the muscles weakened due to continued stress, thereby reducing the stress or tension imposed on the muscles and relieve pain from the latent trigger points.

Kinesio tape decreases muscle tone and alleviates pain by inducing constant relaxation and contraction of muscle through physical stimulation of cutaneous afferents and is effective in maximizing natural healing power by stimulating organs through muscles right under the skin or reciprocal innervation $^{22)}$. As a result, when the latent trigger points were palpated after the taping period, the VAS scores, which were used to measure the pain intensity decreased quite significantly, and the PPT scores were significantly increased. The PPT is designed to diagnose soft-tissue tenderness and evaluate responses to treatment ${ }^{23)}$. The significant increases in PPT scores indicate that Kinesio taping alleviated pain and had positive effects on latent trigger point pain.

The SCM muscle is known to be involved in cervical spine movements as well as to be capable of affecting referred pain in the stomatognathic system or functional disorders ${ }^{24)}$. It is also known to play an important role in adjusting mandibular movements ${ }^{8,25)}$. Head postures are
Table 2. Comparison of PPT, VAS and TMJ ROM within the group, between the groups, and between pre- and postexperiment

\begin{tabular}{lccc}
\hline & Group & Pre-experiment & Post-experiment \\
\hline PPT & 1 & $1.39 \pm 0.15$ & $1.39 \pm 0.59$ \\
$\left(\mathrm{~kg} / \mathrm{cm}^{2}\right)$ & 2 & $1.42 \pm 0.92$ & $1.62 \pm 0.42^{*+}$ \\
VAS & 1 & $4.5 \pm 2.4$ & $4.9 \pm 2.5$ \\
& 2 & $5.10 \pm 2.08$ & $1.95 \pm 1.82^{* *} \ddagger$ \\
ROM & 1 & $40.5 \pm 6.2$ & $40.9 \pm 3.5$ \\
$(\mathrm{~mm})$ & 2 & $39.2 \pm 9.7$ & $41.9 \pm 5.0^{*+}$ \\
\hline
\end{tabular}

1: Control group, 2: Experimental group

${ }^{*} \mathrm{p}<0.05$ significance difference in comparison to pre-experiment;

${ }^{* *} \mathrm{p}<0.01$ significance difference in compared to the pre-experiment

${ }^{+} \mathrm{p}<0.05$ significance difference in comparison to control group; $\$ p<0.01$ significance difference in compared to the control group

maintained for head balance by the SCM muscle as well as many surrounding muscles. The position of the mandible and masticatory muscle tone may be affected by head postures $^{26)}$, and excessive masticatory muscle tone may restrict the ROM of the $\mathrm{TMJ}^{27}$ ). Therefore, latent trigger point in the SCM muscle may lead to head imbalance, which will in turn result in excessive masticatory muscle tone, restriction the ROM of the TMJ. According to the results of this study, pain in the SCM muscle was significantly relieved, and the ROM of the TMJ was significantly increased after the taping period. Therefore, the SCM muscle and masticatory muscle can be said to be closely correlated with each other.

Kinesio taping is thought to be an intervention method that can provide the same effects as soft-tissue massage ${ }^{28)}$, manual therapy ${ }^{29)}$, thermotherapy ${ }^{30)}$, which are methods for alleviating pain in myofascial trigger points, and that can be presented as a method of alleviating myofascial pain in MTrPs in clinics. Since it was identified that excessive SCM tension adversely affected the ROM of the TMJ, the present study revealed that the SCM muscle ha sn important role in restriction of the ROM of the TMJ. A Limitation of this study was the dispersion of the standard deviation for the VAS score, so further studies should be performed with many participants. In addition, since changes in head postures due to pain in the SCM muscle could not be checked in this study, more studies on the effects of the SCM muscle on head postures are considered necessary. 


\section{REFERENCES}

1) Hong CZ, Hsueh TC: Difference in pain relief after trigger point injections in myofascial pain patients with and without fibromyalgia. Arch Phys Med Rehabil, 1996, 77: 1161-1166. [Medline] [CrossRef]

2) Han SC, Harrison P: Myofascial pain syndrome and trigger-point management. Reg Anesth, 1997, 22: 89-101. [Medline] [CrossRef]

3) Dommerholt J: Dry needling-peripheral and central considerations. J Manual Manip Ther, 2011, 19: 223-227. [CrossRef]

4) Myofacial Triffer point therapy-What is it? http://www.myofascialtherapy. org/myofascial-therapy/index.html (Accessed Dec. 23, 2013)

5) Ge HY, Arendt-Nielsen L: Latent myofascial trigger points. Curr Pain Headache Rep, 2011, 15: 386-392. [Medline] [CrossRef]

6) Sternocleidomastoid muscle. http://en.wikipedia.org/wiki/Sternocleidomastoid muscle (Accessed Dec. 05, 2013)

7) Okeson JP: Orafacial pain: Guidelines for assessment, diagnosis and management. Chicago: Quintessence Publishing, 1996, pp 113-184.

8) Ehrlich R, Garlick D, Ninio M: The effect of jaw clenching on the electromyographic activities of 2 neck and 2 trunk muscles. J Orofac Pain, 1999, 13: 115-120. [Medline]

9) Haketa $T$, Kino K, Sugisaki M, et al.: Difficulty of food intake in patients with temporomandibular disorders. Int J Prosthodont, 2006, 19: 266-270. [Medline]

10) What Causes Trigger Points? http://www.painpatterns.com/what_causes trigger_points.html\#what_causes_trigger_points (Accessed Jan. 5, 2014)

11) Simons DG, Travell JG, Simons LS: Travell \& Simons' Myofascial pain and dysfunction: the trigger point manual, 2nd ed. Baltimore: Williams \& Wilkins 1999, pp 94-173.

12) Trigger point. http://en.wikipedia.org/wiki/Trigger_point\#Myofascial pain_syndrome (Accessed Jan. 5, 2014)

13) Kase K, Tatsuyuki H, Tomoki O: Development of Kinesio ${ }^{\mathrm{TM}}$ tape. Kinesio $^{\mathrm{TM}}$ Taping Perfect Manual. Kinesio Taping Assoc, 1998, 6-10: 117-118.

14) Gerwin RD, Shannon $S$, Hong $C$, et al.: Interrater reliability in myofacia trigger point pain syndrome. Pain, 1997, 69: 65-73. [CrossRef]

15) Boonstra AM, Schiphorst Preuper HR, Reneman MF, et al.: Reliability and validity of the visual analogue scale for disability in patients with chronic musculoskeletal pain. Int J Rehabil Res, 2008, 31: 165-169. [Medline] [CrossRef]

16) Ohrbach R, Gale EN: Pressure pain thresholds, clinical assessment, and differential diagnosis: reliability and validity in patients with myogenic pain. Pain, 1989, 39: 157-169. [Medline] [CrossRef]

17) Norkon CC, White DJ: Measurement of joint motion: A guide to goniometry, 4th ed. Philadelphia: F.A.Davis, 2009, pp 409-424.

18) KT method Sternocleidomastoid. http://docs8.chomikuj.pl/503391217,PL, 0,0,Sternocleidomastoid-KT-method.pdf (Accessed Aug. 5, 2013)

19) Macgregor K, Gerlach S, Mellor R, et al.: Cutaneous stimulation from patella tape causes a differential increase in vasti muscle activity in people with patellofemoral pain. J Orthop Res, 2005, 23: 351-358. [Medline] [CrossRef]

20) Murray H: Effects of Kinesio ${ }^{\mathrm{TM}}$ taping on posture and presence of upper extremity pain. http://www.kinesiotaping.com/images/kinesio-association/pdf/research/2001-3.pdf (Accessed Nov. 11, 2014)

21) Examination and consideration of the effects of the stretch rate of kinesio taping on skin: second report. http://www.kinesiotaping.com/images/ kinesio-association/pdf/research/2005-6.pdf (Accessed Jan 5, 2014)

22) What Does Kinesio Taping Do? http://www.kinesiotape.ca/whatitdoes htm (Accessed Nov. 14, 2014)

23) Fischer AA: Pressure algometry over normal muscles. Standard values, validity and reproducibility of pressure threshold. Pain, 1987, 30: 115-126. [Medline] [CrossRef]

24) Leiva M, Miralles R, Palazzi C, et al.: Effects of laterotrusive occlusal scheme and body position on bilateral sternocleidomastoid EMG activity. Cranio, 2003, 21: 99-109. [Medline]

25) Okeson JP: Management of Temporomandibular Disorders and Occlusion, 6th ed. St. Louis: Mosby, 2007, pp 25-30.

26) Kisner C, Colby LA: Therapeutic exercise: Foundation and technique, 5 th ed. Philadelphia: F.A. Davis, 2007, pp 443-455.

27) Bae Y, Park Y: The effect of relaxation exercises for the masticator muscle on temporomandibular joint dysfunction (TMD). J Phys Ther Sci, 2013, 25 : 583-586. [Medline] [CrossRef]

28) Gam AN, Warming S, Larsen LH, et al.: Treatment of myofascial trigger-points with ultrasound combined with massage and exercise - a randomised controlled trial. Pain, 1998, 77: 73-79. [Medline] [CrossRef]

29) Bodes-Pardo G, Pecos-Martín D, Gallego-Izquierdo T, et al.: Manual treatment for cervicogenic headache and active trigger point in the sternocleidomastoid muscle: a pilot randomized clinical trial. J Manipulative Physiol Ther, 2013, 36: 403-411. [Medline] [CrossRef]

30) Lee JC, Lin DT, Hong CZ: The effectiveness of simultaneous thermotherapy with ultrasound and electrotherapy with combined AC and DC current on the immediate pain relief of myofacial trigger point. J Musculoskeletal Pain, 1997, 5: 81-90. [CrossRef] 